\title{
Corneal dystrophy
}

INSERM

\section{Source}

INSERM. (1999). Orphanet: an online rare disease and orphan drug data base. Corneal dystrophy. ORPHA:34533

The term corneal dystrophy embraces a heterogeneous group of bilateral genetically determined non-inflammatory corneal diseases that are usually restricted to the cornea. The designation is imprecise but remains in vogue because of its clinical value. 